\title{
An Autoethnographic Examination of Postpartum Depression
}

Tara Lynn Frankbouser, DO

Nicole L. Defenbaugh, $\mathrm{PbD}^{2,3}$

'Piedmont HealthCare Family Medicine, Statesville, North Carolina

${ }^{2}$ Lehigh Valley Health Network, Allentown, Pennsylvania

${ }^{3}$ University of South Florida, Morsani College of Medicine, Tampa, Florida

\section{बini MORE ONLINE \\ www.annfammed.org}

Conflicts of interest: authors report none.

\section{CORRESPONDING AUTHOR}

Tara Lynn Frankhouser, DO Piedmont Healthcare Family Medicine 208 Old Mocksville Rd Statesville, NC 28625 tara.frankhouser@piedmonthealthcare.com

\begin{abstract}
PURPOSE This article examines postpartum depression (PPD) using autoethnography to explore the stigmatization of depression and cultural expectations of motherhood. Because the personal experiences of living with PPD are often absent from primary care literature, this article uses first-person narrative and analysis of intensive mothering to explore the barriers to seeking PPD treatment, the need for increasing physician confidence and comfort using screening tools, and the impact PPD stigma has on patients and their health care.
\end{abstract}

METHODS Autoethnography, as a relatively unfamiliar methodology in primary care, is used to illuminate individual experiences of living with PPD. The author details a series of encounters as wife, mother, and patient by narrating what it means to live with the disease. A thematic analysis of the series of first-person narratives was employed to further understand the culture of motherhood and shed light on the stigmatization of PPD.

RESULTS Four themes emerged from the analysis revealing the pressures surrounding the cultural ideologies of intensive mothering and the stigma of mental illness: essentialism, failure, shame, and avoidance.

DISCUSSION There is a need to reframe cultural perceptions of motherhood and PPD to positively impact familial interactions and health care encounters for those who live with the illness. The article calls for providing broader diagnostic efforts, more comprehensive care, and engagement with patients in shared decision making around the diagnosis and treatment of PPD.

Ann Fam Med 2017;15:540-545. https://doi.org/10.1370/afm.2107.

\section{THE STORY}

1:47 PM. I feel his feet slide out. I remember it clearly. He is placed on my belly, screaming, as though he needs to prove he exists, this alien sound coming from this tiny being we had created. I hold him and cry, tears of relief that the pain of birth is over, that my son is screaming on my belly. My husband cuts the cord, severing the connection. My son is weighed, printed, wrapped up. They take him to the nursery and wheel me to the floor to recover, ice over my most private parts, now swollen and sewn back together, forever changed by bringing my son into this world.

We brought home a happy, healthy baby boy. My husband was overjoyed, but he was soon back to work as an internal medicine intern with long hours and already limited sleep. I was alone with my son most of the time, surrounded by bottles, breast pump equipment, and dirty diapers.

Months pass. The late afternoon sunshine streams into the hallway from our bedroom while outside the window it dances across yellows and oranges and reds of falling leaves. My back presses against a cold, white door. From behind the door loud wails from deep within my son, as if he were searching for love and a feeling of belonging he had yet to find in my arms. Earlier, we had done the dance-he was fed, his diaper was dry, he had been burped, he had napped. All afternoon we had rocked, walked, I held him close to me, taking in the softness of his skin and hair, the smell that babies have of freshness and powder and milk, and none of it touched me with the deep connection a mother should have with her child. His cries had reached a pinnacle and, scared of what I may do next, I left him 
screaming in his crib-a small soul in a large cage-and closed the door.

The hardness behind me is an opposite to the softness of the carpet under my crossed legs. Next to me sits a halfempty bottle of formula turned on its side, dripping slowly onto the cream carpet beneath. I taste the salt of my tears, not knowing how to help my son or myself. I see only the blurry outline of our hallway, the sunshine a cruel opposite of my dark thoughts. And there I sit gripping the doorknob, white-knuckled, as though it is my only connection to my child. From my lap the screen of my phone brightly displays the time as the minutes slowly pass. I wait for my husband to rescue my child from me. I sit thinking, "What mother cannot soothe her own child for fear of her actions?"

The cries continue in waves as the front door opens and familiar footsteps climb the stairs. I release the knob when a warm hand covers mine, opening the door, and my husband slides past, reaching into the crib to soothe our son. I move towards the sunlight and the respite of our bedroom as I hear the cries turn to giggles behind me.

\section{INTRODUCTION}

As a physician, I thought I understood what it meant for patients to hear a diagnosis of postpartum depression and what treatment was. I had read the statistics about postpartum depression, how it can affect up to $20 \%$ of women 2 weeks to 6 months after delivery. ${ }^{1}$ There are risk factors for the disease, including a history of depression, stressful life events, and a lack of social support. ${ }^{2,3}$ As a physician, I could have diagnosed my own symptoms myself probably months before I addressed them to my own physician. But I was a mother in those moments, buried under feelings of failure and guilt, unable to see a way out. I was lost within the same cultural system patients with postpartum depression navigate daily, internalizing social stigma and holding myself to an idealized good mother standard.

\section{Stigma, Intensive Mothering, and Essentialism}

The social construction of stigma and perceived normalcy are part of the cultural myth of supermom and a belief that women should subscribe to normative standards of intensive mothering. ${ }^{4}$ Intensive mothering is the belief that mothers provide continuous nurturing, expert guidance, and a focus on the child's developmental needs above her own, resulting in an emotionally draining role. Mothers can further isolate themselves by subscribing to essentialism, a belief that mothers are a more qualified and capable primary parent. ${ }^{4}$ Recent research supports the belief that intensive mothering is related to negative mental health outcomes. ${ }^{5}$ The intensive mothering message in treatment guidelines ${ }^{6}$ and self-help books insists that motherhood should bring happiness and, when it does not, medical intervention is necessary. ${ }^{7}$ In stories ${ }^{8}$ and interviews ${ }^{9}$ women express feelings of failure to meet perceived standards of what a mother should be.

Within the frame of postpartum depression, stigma and intensive mothering are deeply interwoven. Internalized mental illness can greatly affect self-efficacy ${ }^{10}$ and the appearance of one's self to others. ${ }^{11}$ With postpartum depression there may be a loss of self that is pervasive, including loss of autonomy and time, as well as transformations in identity. ${ }^{3} \mathrm{~A}$ woman's self-identity may be tied to a mother's self-defined failures to fulfill societal expectations. ${ }^{12}$ Taking on this so-called bad mother identity, coupled with the stigma of mental illness, can inhibit reaching out for help. ${ }^{13}$ As a result, women may be fearful of disclosing symptoms and concerns to health care practitioners. If and when they do seek help, it may be after months or even years, increasing a reluctance to accept treatment. ${ }^{14}$

\section{Screening Challenges: Disclosure, Lack of Training, and Responsibility}

There are numerous recommendations for screening postpartum depression across specialties; however, there remains an overwhelming loss of opportunity to diagnose postpartum depression. Clinicians' lack of comfort with the screening tool or making the diagnosis are some of the most cited reasons across specialties. ${ }^{15}$ Pediatricians, for example, feel they lack the training to properly diagnose and manage maternal depression, even though it has been found that screening is easily implemented at well-baby visits. ${ }^{16}$

And when a woman does seek treatment, she is more likely to be medically bounced from physician to physician in the postpartum period, sometimes without finding anyone willing to steer her to help or hope. Even with clear screening guidelines based in evidence, ${ }^{1,15,17-21}$ clinicians capable of providing the care and guidance these patients seek are lacking. Women with postpartum depression remain lost in a system that seems to be failing them..$^{1,15-18,22}$

\section{Autoethnography as Research Method}

Applying a qualitative lens to postpartum depression can reveal the lived experience of a patient in a larger cultural context. Autoethnography, a type of qualitative research, focuses on the individual story and describes, analyzes, and examines personal experiences to better understand larger cultural constructs, ${ }^{24}$ with a goal "to tell a story in a way that reveals the self as a central character with rich emotional evocation that serves to ground the story being told."25(p79)

Autoethnography parts from narrative as a research method with distinct features and modes of 
inquiry ${ }^{25}$ in that it stems from ethnographic research, a qualitative and systematic methodology. ${ }^{28}$ Although "autoethnography shares the storytelling feature with other genres of self-narrative... [it] transcends mere narration of self to engage in cultural analysis and interpretation." ${ }^{28(\mathrm{p} 43)}$ Autoethnography requires analytical and interpretive rigor, thereby distinguishing itself from self-narrative or other forms of narrative writing, and asks the researcher to frame the story within the context of a particular culture. In this autoethnography, the stories of postpartum depression are not only reflected upon but analyzed within the context of the culture of intensive mothering.

Autoethnography has both a systemic process and a product. ${ }^{24}$ The autoethnographer collects, manages, analyzes, and interprets data and then engages in writing. ${ }^{28}$ The data in autoethnography are both internal (memory, observations, and reflections) and external. The researcher's stories, or internal data, are derived from personal memories. The researcher also draws on external data, such as interviews, artifacts, and previous literature and research, to provide a framework to analyze and interpret the stories. ${ }^{28}$ This systematic investigation of weaving one's personal story with other data provides the framework for analyzing and interpreting the central story within a larger cultural context.

The product of autoethnography resembles an "aesthetic and evocative thick description of personal and interpersonal experience." ${ }^{24(\mathrm{p} 5)}$ The end result is "reader friendly" ${ }^{\prime \prime 2}$ research and an inviting, evocative, and engaging story that often appears to be a simple narrative but has undergone a thorough data analysis and interpretation in line with traditional forms of research.

\section{METHODS}

I chose to write an analytic autoethnography ${ }^{29}$ because of the more traditional research format required ${ }^{30}$ and the systematic method of inquiry in analyzing data. I wrote approximately 20 single-spaced pages of stories during the course of several months. I used self-reflections based on personal encounters with family members and members of the clinical community. Gathering data developed the personal narratives. ${ }^{26}$ I began my analysis early as researcher and participant ${ }_{1}^{28}$ but I conducted a more formal analysis of the stories in a series of steps. In the first level of analysis, I wrote reflective pieces for each story by answering a set of questions (Supplemental Appendix 1, available at http://www.annfammed.org/content/15/5/540/313/ suppl/DC1) to better understand my identity within the social constructs of postpartum depression and my dual role as a clinician and patient within the medical culture. I questioned what I learned about myself from writing and analyzing the narratives and the larger cultural connections. In the second level, I searched for recurring topics in the narratives that became "categorical labels with which data may be fractured and organized." ${ }^{\text {28(p132) }}$ This analysis revealed multiple themes within the full collection of narratives, including abandonment, anticipation, avoidance, discomfort, essentialism, exposure, failure, fear, guilt, incompetence, isolation, a loss of identity, and shame.

After conducting an initial analysis of the narratives, I examined the topics in relation to cultural norms of stigma and intensive mothering, ${ }^{4}$ and identified 4 primary themes: essentialism, failure, shame, and avoidance. In the final level of analysis, I reread the narratives and constructed inclusion criteria: narratives that addressed both a cultural norm and primary theme.

In the Results section I use first-person narrative as the primary structure. Each narrative is followed by a reflection using external sources (literature review) to continue the dialogue between myself (as writer) and the reader. ${ }^{20}$ I layered ${ }^{31}$ my experience chronologically: birth to breastfeeding, silence, breakdown, and, finally, getting help. My story is offset, distinguishing my words from the words of others, and titled according to the themes and subthemes that emerged. I also include the actions and words of others (eg, my husband) to acknowledge my experiences were not alone, even though I may have felt alone at times.

Telling the story using first-person narrative allows a meaningful interaction between personal experience and reflection, which is the basis of experiential learning, ${ }^{32,33}$ and speaks to the nature of autoethnography. This article serves as an invitation to the reader to reflect on each story from her or his own perspective as physician or patient, recognize the themes of stigma and the myth of supermom, and consider the larger cultural implications of living with postpartum depression.

\section{RESULTS}

\section{Intensive Mothering: Isolated Failures}

I buried so much during my son's first few months of life. Under all of the feelings of guilt and failure was a woman screaming silently to be seen and heard without having to say it out loud. Driven by the underlying culture of intensive mothering, I put the needs of my child above my own. ${ }^{4}$ As an essentialist mother, the guilt from prioritizing self-care was overwhelming and prohibitive. ${ }^{9}$ I attempted to handle things on my own. I was unable to reconcile realistic beliefs about mothering with the societal expectations of a good mother. ${ }^{9}$ 


\section{Intensive Mothering: An Essentialist Guilt}

After my husband settles our son in his crib, the soft suck of his pacifier and the white noise of the ocean fading behind his closed door, we retreat to our bedroom. The arm's length distance between us on the bed feels like miles, and the silence stretches on for what seems like hours.

I feel my husband's soft gaze while I study my hands as they become blurred. A hot deluge released from a prison behind my eyes rains down freely, drenching my cheeks, my neck, my chest, and I do nothing to stop it. When finally empty, after minutes of tears without words, I fill the silence. "I don't know what to say." He shifts, closing the space between us Without words he has given me permission to say things I have barely admitted to myself.

In an out-of-body moment, my mouth forms words before I know what I am saying. "I couldn't have him by myself, they had to pull him out of me. I couldn't feed him, instead I starved him hoping we would figure it out, and now instead he takes formula from a bottle because I wasn't able to make any milk. When you're at work, I go through the motions, but I have to put him down. I have to walk away. I don't want to hurt him, but I'm afraid that I might...."

I cannot take back the words once they have been said, but as I feel myself come back together and the tears fall again, they are cool and steady rolling down my face, relief.

Leaning on my husband, even admitting to him that I felt anything but love and adoration for our son, was owning defeat as a mother. I required an assisted birth. I failed at breastfeeding despite seeking out lactation consultants. I felt that I could barely provide our son with his minimal needs. With this in mind, it is no wonder that a diagnosis of depression is viewed as a problem, especially when it interferes with a mother's ability to raise her child, ${ }^{7}$ with some researchers noting "effective mothering is a public health concern." 34

\section{Stigma: Avoiding Help}

I'm in a plastic chair, the same chair I sit in for any doctor's appointment, the walls covered in posters reminding diabetics to take off their shoes and ask for refills before leaving, magazines dishing on the latest fashion trends and celebrity drama. A room like so many I have been in during my medical training, but so different at the same time. I am the patient now, and the hard, unfeeling plastic chair clearly defines the roles.

I called this morning and spoke to the receptionist. When she asked, "Why do you need to see the doctor?" "Migraines" rolled off my tongue quickly and easily, a problem severe enough to be seen today. She quickly made the appointment.

I sit and fidget, crossing and recrossing my legs, checking the time on my phone, staring at the door, thinking, "What if I don't get better? What if I can't love this beautiful little boy? What if I can never be enough for him because I am too much of an emotional wreck? What if I hurt him?" A solitary knock jars me back to reality.

I realize now that the delay in my diagnosis and treatment was multifactorial. Because of my own fear of stigma and treatment, I postponed a visit to my physician; I worried because I had nothing physical to show. ${ }^{35}$ More than that, the many clinicians I had seen since giving birth had not looked for postpartum depression. My son's pediatrician believed the face I put on for the world and the "I'm fine" response to the question "And how's mommy doing?" at each of 5 visits before I sought help from my primary care physician. My obstetrician breezed in and out of my postnatal visit and assessed that stitches had healed since delivery. I initiated the eventual encounter with my physician out of overwhelming fear and desperation, which finally outweighed the once primary stigma and failure. ${ }^{1,19,36,37}$

\section{Stigma: For Shame}

A familiar face, stethoscope hanging from his neck, pokes his head into the room, smiling. As the solid wooden door clicks shut behind him, he immediately voices concern, "What are we going to do about these headaches?"

I cut him off. "That's not why I'm here today; I just needed an appointment to see you." I inhale a slow, deep breath and let the words flow from me, the words that scare me, that sicken me, that make me feel like I am anything but the mother I should be. "I think I'm depressed, and I think it's because of that beautiful little guy sleeping there. He just cries. And he's fed, and clean, and rocked, and burped, and I don't know what else to do, so I put him in his crib and let him scream. Because I don't know what I would do if I didn't leave him there and walk away...." Looking down, I finish my thought. "We have this perfect, happy little boy. We wanted him, and this is all I can feel for him? What kind of mother am I?"

He passes the tissues, quietly, and asks the standard questions. "When did it start?" to which I reply, "Probably months ago, but it's gotten worse."

"Have you talked to anyone about this before coming in today?"

"Only my husband, last night."

"Have you thought about hurting yourself?"

"No" was a fast, truthful reply.

"Have you thought about hurting the baby?"

The silence stretches on as I hear my breathing quicken and my pulse race in my temples. "I wouldn't hurt him. I don't want to hurt him. I just put him down and walk away when I feel like I can't take it anymore. But that's not the mother I feel like I should be." 
The American College of Obstetricians and Gynecologists and the American Academy of Pediatrics support routine screening for postnatal depression at perinata, postnatal, and well-infant visits, but they report barriers, including a lack of experience and comfort with diagnosis and treatment and a lack of referral base for support services for women. In primary care in particular, screening is a burden. ${ }^{15,17,19,25,38}$

\section{DISCUSSION}

\section{Intensive Mothering: Social Class and Risks of Postpartum Depression}

Although my story details the experiences of a white, middle-class, highly educated woman, the American ideal of intensive mothering spans different strata. In addition to white, middle-class women, ${ }^{4}$ research has shown that low-income minorities subscribe to the ideals of supermom and being the essential parent, feeling similar failure and shame. ${ }^{11}$

Accepting the cultural standards of motherhood may be a risk for developing postpartum depression. Even with family support, the belief in essentialism is related to lower satisfaction with life. ${ }^{5}$ The fear of society labeling a woman as a bad mother can lead to shame and avoidance in seeking treatment. ${ }^{12} \mathrm{My}$ experiences with postpartum depression showed me that I not only fully subscribed to intensive mothering norms, it subconsciously helped shape my depression and postpone my own treatment.

\section{Screening: Addressing the Challenge of Postpartum Depression}

Medical professionals across primary care specialties have a responsibility to ensure that these conversations are occurring in our offices. My own experiences were fraught with missed opportunities, leaving me to find my own physician for treatment. Additionally, I had to find a way to verbalize what I was ashamed of feeling to receive treatment. Screening might have helped alleviate some of this burden and may have led to an earlier diagnosis.

The most widely recognized and used postpartum depression screening tool is the Edinburgh Postnatal Depression Scale. ${ }^{21}$ A more commonly used screening tool for depression, the Patient Health Questionnaire, is also available for screening postpartum depression. ${ }^{39}$ Although no ideal tool has been identified, the goal is to screen for depression using a tool the clinician is comfortable interpreting to start the conversation.

\section{Autoethnography as a Method for Medical Research}

Autoethnography is primarily used by patients to describe their illness experiences. ${ }^{40,41}$ Even though it has shown benefit when applied to medical practice, ${ }^{26}$ it has yet to be fully adopted by the medical community. As a research method it brings light to experiences normally kept hidden and silent while staying true to foundational research principles. I chose to expose my most vulnerable moments ${ }^{25}$ and admit my failures to influence the culture of medicine and introduce a new method to primary care. We can approach research in a way that parallels how we approach our patients, in conversations about symptoms, diagnosis, and treatment. Autoethnography has the potential to teach us about the power of personal narrative as a means to further understand topics of medical importance.

\section{AFTERWORD}

It has been 5 years since that appointment when I described my postpartum depression, when my world crashed around me and I left with a piece of paper prescribing an antidepressant, things have changed. There are now 3 small children racing around my feet, laughing, singing, dancing. I have stopped and started medications during pregnancies, I struggled less with admitting I was sliding back into the dark place of failure and guilt after our daughter's birth, and even put myself first by starting treatment before giving birth to our third child. I know that motherhood is not neat and clean and perfect, that the ideals I tried and still try so desperately to live up to are not realistic. I know that there is no way to wrap up my story with a pretty bow. Instead, I smile at the chaos around me, the toys strewn across the floor, and the giggles and songs my children share with me, knowing that I slowly make progress every day. And more than that, I am blessed and humbled to help others do the same, asking questions of the moms I now care for as a physician. Holding my patients' hands, I hold back my own tears, and we start together down a road of healing.

As physicians, we hear patient stories every day; it is part of the practice of medicine. I hope physicians can share my story with patients and their families when patients need to know that they are not alone, that their disease will not define them, and that they can find the courage to share their own story as they start down a path to healing with their physicians.

To read or post commentaries in response to this article, see it online at http://www.AnnFamMed.org/content/15/6/540.

Key words: depression, postpartum; autoethnography

Submitted April 14, 2015; submitted, revised, December 4, 2016; accepted February 16, 2016.

Previous presentations: This research was presented at the International Congress of Qualitative Inquiry, May 2014, in Urbana-Champagne, Illinois.

Acknowledgments: William Miller, MD, provided guidance and support; Elissa Foster, PhD, provided feedback on autoethnography as a 
relatively new method of medical research; and Jacqueline Grove provided editorial help. A special thank you to the Frankhouser family for their love and support through this experience.

Supplementary materials: Available at http://www.AnnFamMed. org/ content/15/6/540/suppl/DC1/.

\section{References}

1. Stowe ZN, Hostetter AL, Newport DJ. The onset of postpartum depression: Implications for clinical screening in obstetrical and primary care. Am J Obstet Gynecol. 2005;192(2):522-526.

2. Knudson-Martin C, Silverstein R. Suffering in silence: a qualitative meta-data-analysis of postpartum depression. J Marital Fam Ther. 2009;35(2):145-158.

3. Edhborg M, Friberg M, Lundh W, Widström AM. "Struggling with life": narratives from women with signs of postpartum depression. Scand J Public Health. 2005;33(4):261-267.

4. Hays S. The Cultural Contradictions of Motherhood. New Haven, CT: Yale University Press; 1996.

5. Rizzo KM, Schiffrin HH, Liss M. Insight into the parenthood paradox: Mental health outcomes of intensive mothering. J Child Fam Stud. 2013;22(5):614-620.

6. Pape KM. Mothering and the Functional Self: A Hermeneutic Exploration of Texts on Perinatal Mood and Anxiety Disorders [dissertation]: Seattle, WA: Antioch University; November 2014.

7. McMillen KM. Postpartum Depression and Self-Help Books: Medicalizing Misery and Motherhood [master's thesis]. Atlanta: Georgia State University; 2009.

8. Thomas LJ, Scharp KM, Paxman CG. Stories of postpartum depression: exploring health constructs and help-seeking in mothers' talk. Women Health. 2014;54(4):373-387.

9. Knaak S. "Having a tough time": Towards an understanding of the psycho-social causes of postpartum emotional distress. J Assoc Res Mothering. 2009;11(1):80-94.

10. Corrigan PW, Watson AC, Barr L. The self-stigma of mental illness: implications for self-esteem and self-efficacy. J Soc Clin Psychol. 2006;25(8):875-884.

11. Goffman E. The Presentation of Self in Everyday Life. Garden City, NY: Doubleday; 1959.

12. Abrams LS, Curran L. Maternal identity negotiations among lowincome women with symptoms of postpartum depression. Qual Health Res. 2011;21(3):373-385.

13. Beck CT. Postpartum depression: a metasynthesis. Qual Health Res. 2002;12(4):453-472.

14. Dennis CL, Chung-Lee L. Postpartum depression help-seeking barriers and maternal treatment preferences: a qualitative systematic review. Birth. 2006;33(4):323-331.

15. Gjerdingen DK, Yawn BP. Postpartum depression screening: importance, methods, barriers, and recommendations for practice. J Am Board Fam Med. 2007;20(3):280-288.

16. Freeman MP, Wright $R$, Watchman $M$, et al. Postpartum depression assessments at well-baby visits: screening feasibility, prevalence, and risk factors. J Womens Health (Larchmt). 2005;14(10):929-935.

17. Committee on Obstetric Practice. The American College of Obstetricians and Gynecologists Committee Opinion no. 630. Screening for perinatal depression. Obstet Gynecol. 2015;125(5):1268-1271.

18. Earls MF; Committee on Psychosocial Aspects of Child and Family Health American Academy of Pediatrics. Incorporating recognition and management of perinatal and postpartum depression into pediatric practice. Pediatrics. 2010;126(5):1032-1039.
19. Seehusen DA, Baldwin LM, Runkle GP, Clark G. Are family physicians appropriately screening for postpartum depression? J Am Board Fam Pract. 2005;18(2):104-112.

20. Yawn BP, Bertram S, Kurland M, Wollan PC. Repeated depression screening during the first postpartum year. Ann Fam Med. 2015;13(3):228-234.

21. Shakespeare J, Blake F, Garcia J. A qualitative study of the acceptability of routine screening of postnatal women using the Edinburgh Postnatal Depression Scale. Br J Gen Pract. 2003;53(493): 614-619.

22. Langan R, Goodbred AJ. Identification and management of peripartum depression. Am Fam Physician. 2016;93(10):852-858.

23. Miller WL, Crabtree BF. Clinical research. In: Denzin NK, Lincoln YS, eds. Handbook of Qualitative Research. 2nd ed. Thousand Oaks, CA: Sage Publications; 2000:607-631.

24. Ellis C, Adams TE, Bochner AP. Autoethnography: an overview. Historical Social Research. Hist Soz Forsch. 2011;12(1):273-290.

25. Anderson L, Glass-Coffin B. I learn by going: autoethnographic modes of inquiry. In: Jones SH, Adams T, Ellis C, eds. Handbook of Autoethnography. New York, NY: Routledge; 2016: 57-83.

26. Foster E. Values and the transformation of medical education: the promise of autoethnographic research. J Med Person. 2013;11(1): 19-23.

27. Frank A. The Wounded Storyteller: Body, Illness, and Ethics. Chicago, IL: University of Chicago Press; 1995.

28. Chang H. Autoethnography as Method. Walnut Creek, CA: Left Coast Press; 2008.

29. Anderson L. Times is of the essence: an analytic authoethnography of family, work, and serious leisure. Symbolic Interact. 2011;34(2): 133-157.

30. Chang H. Individual and collaborative autoethnography as method. In: Jones SH, Adams TE, Ellis C, eds. Handbook of Autoethnography. New York, NY: Routledge; 2016:107-122.

31. Ronai CR. Multiple reflections of childhood sex abuse: an argument for a layered account. J Contemp Ethnogr. 1995;23(4):395-426.

32. Kolb D. Experiential Learnings: Experience as the Source of Learning and Development. Englewood Cliffs, NJ: Prentice Hall; 1984.

33. Moon J. A Handbook of Reflective and Experiential Learning: Theory and Practice. New York, NY: Routledge/Falmer; 2004.

34. Logsdon MC, Wisner KL, Pinto-Foltz MD. The impact of postpartum depression on mothering. J Obstet Gynecol Neonatal Nurs. 2006; 35(5):652-658.

35. Reich WA, Silbert-Mazzarella BA, Spence JA, Siegel HI. Selfstructure and postpartum dejection in first-time mothers. J Psychol. 2005;139(5):426-438.

36. Beck CT, Indman P. The many faces of postpartum depression. J Obstet Gynecol Neonatal Nurs. 2005;34(5):569-576.

37. Bell RA, Franks P, Duberstein PR, et al. Suffering in silence: reasons for not disclosing depression in primary care. Ann Fam Med. 2011;9(5):439-446.

38. Gjerdingen D, Crow S, McGovern P, Miner M, Center B. Postpartum depression screening at well-child visits: validity of a 2-question screen and the PHQ-9. Ann Fam Med. 2009;7(1):63-70.

39. Arroll B, Goodyear-Smith F, Crengle S, et al. Validation of PHQ-2 and $\mathrm{PHQ}-9$ to screen for major depression in the primary care population. Ann Fam Med. 2010;8(4):348-353.

40. Defenbaugh NL. Under erasure: the absent ill body in doctorpatient dialogue. Qual Inq. 2008;14(8):1402-1424.

41. Defenbaugh NL. Dirty Tale: A Narrative Journey of the IBD Body. New York, NY: Hampton Press; 2011. 